\title{
Service Failure Recovery in the Sharing Economy: A Case Study of Airbnb
}

\author{
Luis Sosa \\ San Diego State University \\ 1sosa2518@sdsu.edu \\ Farzan Koobchehr \\ University of California, Irvine \\ khoobchf@uci.edu
}

\author{
Kaveh Abhari \\ San Diego State University \\ kabhari@sdsu.edu \\ Bo Xiao \\ University of Hawaii at Manoa \\ boxiao@hawaii.edu \\ Fernando Olivares \\ San Diego State University \\ folivares8401@sdsu.edu
}

\author{
Michael Pesavento \\ San Diego State University \\ mpesavento2308@sdsu.edu \\ Pocky Kohsuwan \\ San Diego State University \\ pkohsuwan7724@sdsu.edu
}

\begin{abstract}
Sharing platforms are becoming increasingly common, revolutionizing how peers interact and share resources across an array of online applications. While the sharing economy itself is established, less is known about service failures and corresponding recovery strategies that are relevant to it. This research investigates the myriad effects of service failures (and their associated recovery strategies) on customer experience in the digital sharing economy. Findings suggest that different service failure strategies exert differing effects on customer experience, which subsequently affects the behavior towards the service being provided and the service provider. The suggestions given here respond to important implications for research and practitioners by offering new ways to explore and detect service failures and possible recovery strategies.
\end{abstract}

\section{Introduction}

The emergence of new social technologies, and entrepreneurial opportunities in the past decade has contributed to the establishment of what has been dubbed the "sharing economy". The term "sharing economy" refers to a shift in market strategy from ownership towards temporary access to underutilized resources [1]. This novel approach has manifested in a variety of unique forms, from sharing operand resources (such as tools) to sharing operant resources (such as ideas) [2]. For the purposes of this paper, we define the sharing economy as customers granting each other temporary access to underutilized resources (idle capacity), for money without transferring the ownership [3], [4]. This service-oriented process may 'fail' to meet expectations a variety of reasons and thus, lead to dissatisfaction among the peers and negativity toward the platform provider. We conceptualize this possibility as service failure in the sharing economy.

In this study, we attend to an important research gap, given that research into the concept of service failure has mainly focused on the product market and limited attention has been provided to service failure in the sharing economy. Hence, the goal of this study is to offer a better understanding of service failure in the sharing economy specifically and classify the possible recovery strategies addressing those failures. We attempted to achieve this goal through a case study of Airbnb. We investigate the main categories of service failure, and whether the measures Airbnb takes to recover service failure provide helpful conflict resolutions to their customers.

\section{Background}

Sharing economy platforms (platforms) are enabled by social mechanisms that connect people who want to share resources, and technology that enable transactions and exchange between the peers [5], [6]. Relevant sharing economy examples include large-scale services such as Airbnb, and Uber [7]. The dynamic nature of these and other platforms have challenged and transformed the "traditional" conceptualization of value creation, delivery, and capture in the service industry. To that point, the transformation prompted by these new industry titans has led to a more complex customer relationship dynamic, service expectation, and reliance that are 
difficult to model and understand through established ecommerce literature alone [8]-[10]. As such, the following subsections lay the groundwork for this study's conceptual expansion.

\subsection{Service Failure}

'Service failure' indicates that perceived service performance by a firm falls below customer expectations and thus customers experience dissatisfaction [11]. Service failures constitute a major problem for firms, as the inconsistency of service quality and efficiency can make it difficult for customers to accurately build an expectation about service enablers' capabilities and commitment [12]. Extensive studies have indicated that service failure generally results in substantial costs for organizations, particularly in terms of customer retention and online reviews [13], [14]. While a well-built customerbusiness relationship can potentially shield a service provider from the negative effects of service failure for in the short-term [15], repeated failures could lead to irreversible negative consequences for the business's performance and reputation [16], [17]. This is not an uncommon, or even entirely avoidable scenario. All companies are likely to stumble in their provision of products or services at some point in time, and even excellent service providers sometimes face unavoidable service failures. While companies cannot guarantee flawless service, they can ensure that the service failures will be recovered in accordance with their customer expectations. Given this, it is paramount to the success of service firms to identify potential service failures before they happen (to minimalize customer exposure to potential failures) or recover the failures to retain the customer and maintain positive market presence.

\subsection{Service Failure in the Digital Economy}

There are three major areas of service failures in the digital economy: informational, systems, and functional failures [18]. While these failure categories are relevant to the sharing economy, they cannot fully capture the full spectrum of potential service failures in the online domain. Instead, these few exemplary failure types were chosen for their representative value as major service failure categories. Service failures require managers to work on problem areas, address customers' concerns, and improve their service processes to minimize similar problems in the future [19]. Therefore, it is necessary to detail what each failure is composed of.

Informational Failure. Informational failure is a major service failure category [20], and constitutes a failure (either implicit or explicit) to provide appropriate, reliable and timely informational data that is of interest of customer for decision-making. For example, information failure in ecommerce sites entail failure in providing accurate information on products, listing inconsistent information on pricing, or having unreasonable wait times for customers to receive information. This type of failure is relevant to the sharing economy since these platforms typically use ecommerce methods for listing, promotion, and transaction. Similarly, informational attributes (e.g., accuracy and timeliness) as crucial antecedents of service outcome quality [21]. Therefore, if any of these antecedents are not met, it constitutes an informational service failure.

Informational Failure Consequence. Informational failures abound in a digital landscape, and consequently have a significant impact on consumer satisfaction and loyalty. As existing studies of consumer satisfaction and service quality affirm, the information employed by customers in making decisions impacts outcome predictability [22]. That is, if misinformation were to be supplied by a platform, whether intentionally or unintentionally, customers may be misled into acquiring services that do not fit their needs. Due to this potential for miscommunication, the consequences of an informational service failure may range from immediate dissatisfaction to long-term disillusionment with a brand and its products.

Furthermore, informational failure in the sharing economy has the potential to undermine firms' relationships with their customers as well customers and customers and simultaneously elevate operational costs. Prior studies in this domain also suggest that an informational failure can result in loss of customer trust and lower customer satisfaction with a given firm [23]. Reduction in customer trust and satisfaction can have wide reaching ramifications for firms, such as lower customer repurchase intentions, higher customer attrition, and less success of customer acquisition efforts [24]. To stem these losses, firms will be required to expend efforts to assuage customers [24], increasing their ex-post relational costs.

Systems Failure. Systems failures are a major variety of service breakdowns that occur when a system error, staff error, or the consumer's own mistakes impose a contrary experience to established quality and service expectations [25]. Systems failures are characterized by technological inaccessibility, non-adaptability, non-navigability, delay, and insecurity, all of which affect the outcome of a service or transaction [26]. Sometimes these issues can be corrected in seconds or less through dynamic and automatic error detection and recovery [27]; however, if not, they may lead to serious retention issues [28]. 
System failures are also common on sharing economy platforms regardless of their business domains and business models. Due to the nature of some technical errors on these platforms and the time needed to analyze them, some failures cannot be prevented at the time. Despite this, technologies can enable the platforms to prevent similar systems failures occurring in the future. However, constantly monitoring all the services needed for client satisfaction entails significant resources, so to optimize cost, platforms utilize technology enablers (e.g. online chat capabilities/tutorials) to communicate in a way that can prevent, or at least minimize, the probability of systems failures occurring [27].

Systems Failure Consequence. Systems failures represent a potentially damaging type failure for platforms and customers alike, as their rectification often carries significant cost considerations [29]. For example, system failures may lead to consumer retribution behaviors like posting dismissive online reviews [30]. These failures also highly discourage customers from allowing service providers to recover the failure that occurred. Therefore, system failure is more challenging to be recovered than information failures on platforms. Studies have also demonstrated that system failures such as delay induce a sense of loss in customers (because they are forced to spend more time than projected in acquiring the service) [31] and they may lead to service request termination [32]. Additionally, systems failures lower customers' effort-performance expectancy, as a much higher transactional cost must now be incurred to attain satisfactory service performance [33][34]. Conversely, resource investments promoting system characteristics such as accessibility, adaptability and navigability have a significant impact on lowering customers' transactional costs overall [35]. This indicates that, in instances of systems failure, the inability or unwillingness to address system issues incurs significant penalties for all stakeholders.

Functional Failure. Functional failures, sometimes referred to as "process failures", describe the customer's perception of the various interactions during the service encounter [36]. Functional failures are associated with failing in satisfy customers' transactional needs [37]. Regardless of the business process design or intent, if the functionalities of a platform cannot meet customers' needs, any design improvements may be rendered moot. Functional failure is comprised of five elements, each of which may affect a transaction to varying degrees. These elements are need recognition, alternative identification, evaluation of alternatives, acquisition, and post-purchase failures [26]. A well designed platform for the sharing economy should minimize these five types of failures for smooth purchasing process and overall positive experience [18]. Needs recognition failure refers to the functionalities of a service being incapable providing a given need or preference of the customers [26]. Alternatives identification failure occurs when functionalities of a service are not able to assist customer in identifying alternatives to the products or services offered. Evaluation of alternatives failure refers to an inability to assist the customer in evaluating the service options. Acquisition failure refers to an inability to convincing customers in acquiring the services offered. Postpurchase failure occurs when the functionalities of a service are not able to assist the users to: a) track the services purchased; b) provide suggestion on how to use the services in order to get the maximum gain, or c) terminate the services which are not needed [26].

Functional Failure Consequence. Functional failures in the sharing economy are unavoidable and may present significant difficulties to the customers and firms if left unaddressed [37]. These failures may take a variety of shapes based on the business domain. However, the ability to address these failures may lead to performance setback for all parties. For example, disproportionate traffic pressure may cause the platform functionalities to be compromised rendering it incapable of servicing the customer's requirements during the purchase process [38]. These failures may include the platform crashing, becoming inaccessible during the purchase process, or increasing the customer efforts for making a purchase during a timeconstrained event [39].

\subsection{Need for a New Perspective}

Service providers of all varieties face errors in service delivery, which may have lasting impacts on consumer loyalty and brand image [15]. Prior research quantifies the consequences of service failures in online retailing, concluding that reducing service failures and implementing appropriate recovery strategies can net a positive effect on customer retention [33]. Fast identification and correction of these errors can prevent them from becoming manifest service failure in the minds of customers, since they are corrected before the customer is made aware that they have occurred. Therefore, it is important to understand the consequences of each major service failure category to plan and adjust for each.

Despite the need for pragmatic functionality in all forms of service offering [37], [40], research indicates that customers' expectations in the sharing economy are not fully comparable with those of ecommerce [37], [39], [40]. Our current understanding is limited to what we know from research on ecommerce. Thus, 
our current understanding of service failure recovery strategies in the sharing economy is also limited to the service expectation management models in ecommerce (e.g. transactional standards of ecommerce websites [40]). Therefore, a new perspective is necessary to address the service failure recovery challenges specific to the sharing economy. Among the possible explanations, we focused on two.

First, sharing economy platforms, enabled by various information systems, are likely to experience higher operational costs related to fixing the processes responsible for service failures due to complexity, synchronicity and multifarious [16]. For example, in instances of systematic informational failure, these platforms need to go beyond processing customer refund and directly invest in improving the systems to give confidence to all parties that similar information failures would not happen in the future.

Second, it is expected that higher relational costs would accrue for a platform following service failures. Unlike e-retail, to provide restitutions to customers' loss, sharing economy platforms need to expend more resources in relationship and trust recovery and thus incur higher relational costs [24]. This high relational cost is attributed to the complexity of peer-to-peer network of customers where addressing the failure entail more than one external entity. In the sharing economy, service failures is not only a service process issues [41], but a value-network issue that may result in negative spillover effects on all participating actors' perceptions of the network and above that, peer-topeer business models in general [42].

\section{Method}

We conducted an exploratory case study to answer our research questions: (1) "What are key service failure categories specific to the sharing economy?" and (2) "How can these failures be recovered?" The impetus for these questions is rooted in inconsistent information regarding service failures in general, and a lack of exploratory research into service recovery strategies in the ecommerce sphere.

To approach these questions, we collected and analyzed customer reviews for Airbnb on two independent customer review communities, Trustpilot and AirbnbHell. Airbnb is one of the world's leading sharing economy platforms to date, where peers can share and exchange tangible resources for lodging as well as intangible resources such as time and experiential knowledge [43]. Airbnb's diverse forms of sharing, archetypal interactions between the parties, personalization possibility, business success, socioeconomic impact, and popularity are the most prevalent justifications for the use of the platform for this research. Using Airbnb as a case study also enables our research to engage the interactive and experiential components of sharing economy services.

We used comments from the AirbnbHell and Trustpilot communities as our data resources. These platforms provide a collection of uncensored stories from both guests and hosts of Airbnb rentals. For the sake of this study, we limited the dataset to the stories shared on these platforms that contain both service failures and recovery strategies (regardless of how they perceived by the guests or hosts).

Data only consisted of 400 textual reviews (stories) from guests and hosts (200 from each data source), divided by meta data such as rating and date. The stories typically contain more than one failure (three in average). The accommodations for which comments were provided ranged from an entire house/home, to a private room in a house or apartment, to a shared room in a house or apartment. To control for the possible effects of context, we only used data from popular travel destinations which have numerous accommodation listings and stories.

We used three-step content analysis approach that included open-coding, axial-coding and selective coding. This approach was considered most applicable given the lack of previous analysis of comments and was informed by previous work on open online exchanges (e.g. [44], [45]). The open-coding process led to breaking down the stories into list of service failures and the axial coding allowed us to discover the relationships between the codes and accordingly classified them into 24 core concepts. Finally, we group the 24 concepts into four service failure groups. We also identified three main groups of recovery strategies corresponding with the identified failures.

\section{Case Study Results}

This section details the results of our investigation into customer responses to Airbnb service failures. The sources of failure identified in this section show that, despite the potentially high reward for embracing a sharing economy model, firms that do are faced with certain inherent risks of service failure [5]. Each of these issues present unique instances of service failure which need to be addressed to ensure the least ramifications to businesses. The content analysis process helped identify four groups of service failures based on the identified 24 concepts.

The first group of failures was related to process failure and are mainly handled by the platform itself. The process failures were either related to platform technology (e.g. processing payment) or service acquisition experience (e.g. recommendation). We observed that most technology-related failures were 
"objective," meaning these failures were interpreted by all the users in the same way (e.g. system failure to record a reservation). Conversely, service acquisition failures were interpreted as "subjective," or varied from party to party (e.g. Airbnb cancelation policy).

Further, we identified a group of comments related to service outcomes. Many stories that we studied contained comments related to the accommodations' cleanliness, amenities, location, guest-host interactions etc., and thus, we categorized these failures as outcome failure. Much like process failures, outcome failures were interpreted both objectively and subjectively. Some failures in this category were associated with the service quality (e.g. access to accommodation, accuracy of information provided by host, or consistency service). However, some service outcome failures were attributed to the guest/host experience and are open to interpretation (e.g. guest attitude or host friendliness). Table 1 lists some examples that fall under the main categories and subcategories that emerged from our three-phase coding process. In the following section we discuss these categories of failures in more detail.

\section{Table 1. Categories, sub-categories, and code examples}

\begin{tabular}{|c|c|c|}
\hline CAT. & SUBCAT & EXAMPLE OF CODES \\
\hline \multirow[t]{2}{*}{$\begin{array}{l}\text { Process } \\
\text { Failure }\end{array}$} & $\begin{array}{l}\text { Service } \\
\text { Technology }\end{array}$ & $\begin{array}{l}\text { - Acquisition technology: payment, } \\
\text { refund process, customization } \\
\text { - Communication technology: } \\
\text { Information, security and privacy, } \\
\text { account management } \\
\text { - Customer service technology: } \\
\text { reliability, speed, simplicity }\end{array}$ \\
\hline & $\begin{array}{l}\text { Service } \\
\text { Acquisition } \\
\text { Experience }\end{array}$ & $\begin{array}{l}\text { Personalization: Freedom of choice, } \\
\text { recommendations, product comparison } \\
\text { Customer service team: } \\
\text { responsiveness, empathy, accessibility, } \\
\text { flexibility, support } \\
\text { - Control: process ease, risk, } \\
\text { transparency, intuitiveness }\end{array}$ \\
\hline \multirow[t]{2}{*}{$\begin{array}{l}\text { Outcome } \\
\text { Failure }\end{array}$} & $\begin{array}{l}\text { Service } \\
\text { Function }\end{array}$ & $\begin{array}{l}\text { - Service promises: accuracy, } \\
\text { consistency, access, safety, location } \\
\text { - Service value: Value }\end{array}$ \\
\hline & $\begin{array}{l}\text { Service } \\
\text { (Outcome) } \\
\text { Experience }\end{array}$ & $\begin{array}{l}\text { - Social experience: socialize or } \\
\text { interaction with host or other guests } \\
\text { - Emotional appeal: surprise, peace of } \\
\text { mind, friendliness } \\
\text { - Act experiences: activities, privacy }\end{array}$ \\
\hline
\end{tabular}

\subsection{Process Failure}

Process failures are failures that take place during a transaction and service acquisition. Though these failures are specific to the process of a transaction, they play a significant role in generating negative sentiment. The following sections describe two identified process failure categories-service technology failures and service acquisition experience failures. Each of these categories may be uniquely composed of different process failures.

Service Technology Failure. As our findings indicate, in the context of Airbnb service delivery process failures related to the platform technology can be attributed to typical systems failures that are discussed in ecommerce and e-governance literature. These failures were reported in about half of the customer stories we collected from Trustpilot and AirbnbHell. Since these varieties of service failures are closely related to the Airbnb platform itself, we labeled them as 'service technology' failures. Consistent with previous studies [26], these failures were typified by the platform's lack of accessibility, clarity, adaptability, navigability, as well as technical errors and delay-for example, when customers found the platform (web or mobile app) difficult to use due to lack features and functionalities.

Our data shows that there are notable number of service acquisition failures related to platform technology. For example, about $8 \%$ of reported issues in this domain were associated with processing payments and refunds (e.g. platform failure in processing payment or mistake in processing refund). These are failures where Airbnb had issues completing the transactional portion of the agreement (i.e. Airbnb systems failed to facilitate a transaction properly). For example, one customer reported: "Poor customer phone service. Cause on website could not change date." Another claimed that, "Reservation was cancelled since verification is claimed to be a painting and funds are on hold for 5 days." We grouped these failures along with other issues related to reservation and cancelation under acquisition technology.

Communication failures were the second most common group of failures related to the platform technology. These failures constitute customers' problems or difficulties in encountering and engaging the data that was provided to them through the Airbnb platform (e.g. listing, recommendations, user profile). For instance, guests complained about "Prices did not shown [sic] up as setup," or "Last minute cancelation of reservation without notification." We grouped these failures along with other information related issues (e.g. communication privacy) into a category we labeled communication technology failures. Service failures under this category had a failure rate of $9 \%$ in our dataset. and were mainly precipitated by the Airbnb platform's failure to accurately communicate about an inquiry a customer had, or otherwise failed to communicate a necessary or relevant message through their platform. This suggests that the necessity for timely, accurate, and encompassing information exchange between all stakeholders (Airbnb, hosts and guests) is cornerstone to the platform's success. 
Finally, customer service (which commanded the lion's share of systems failures) maintained the highest failure rate at $35 \%$. Some of these claims are related to the objective aspects of customer service such as reliability, availability, speed, simplicity; as such we grouped them under customer service technology. Conversely, the subjective aspects of customer service not related to the technology platform were grouped under service acquisition experience, which is discussed in the next section. Service technology failures in customer service were mainly associated with the lack of service orientation in digital transactions with Airbnb hosts. This is consistent with research indicating that, even across companies, customers reported a lack of customer support when service failures occurred [10]. As such, this common complaint can be demonstrative of a more general caution, as an attention to customer service could reduce the single highest category of systems failures.

Service Accusation Experience Failure. As with other failure categories, process failures were also subjectively received and interpreted by Airbnb customers (both guests and hosts). We did not observe a significant number of associations between this subcategory of failures and Airbnb platform technology. Hence, we grouped them independently. The associated data showed that customers value their experience even more than they value mechanical aspects of ecommerce transactions. Instead, the context of Airbnb transactions places an experiential premium on characteristics like well-vetted, accessible and personalized information provided by supportive and flexible hosts.

Despite the best efforts of Airbnb, process experience failures are bound to occur. In this study, we identified a set of negative subjective experiences during the process of service acquisition on the Airbnb platform and thus grouped them under a new subcategory labeled service acquisition experience failures. Based on the sentiments of the analyzed stories, these failures seem to have had an adverse effect on customers' perception of the brand. It was also evident that the lack of recovery attempts after an initial disappointment in service experience significantly compounded customer dissatisfaction. Under this domain, we identified three sources of experience failures: personalization, customer service, and sense of control.

Failure related to process personalization (or personalized responses) represented a significant variation in customer expectation. About 14\% of reviewed stories reflected some form of customers' expectation for personalization, accommodation of personal needs, or special treatment during the service acquisition process (e.g. cancelation because of personal emergency). Lack of support from Airbnb's service team accounted for $10 \%$ of variation in the coded data. For example, the lack of support protocol from Airbnb for multiple guests sharing amenities was noted in different stories. Insufficiently trained and/or unfriendly support personnel were other issues presented in some stories (e.g. "Had to fight through bank and phone calls to get a full refund from a lastminute cancelation from host"). Service experience failures could be also attributed to the lack of control by both guests and hosts. The dataset helped explain that a significant percentage of process related failures (5\%) occur since customers perceived high risk or low control over the process. Some examples of this type of failure are guests having to make a risky decision during the reservation process; guests having to communicate with the host; or when a host's perceived lack of transparency makes for unhappy guests.

\subsection{Outcome Failure}

Outcome failures occur at the end of the transactional process when a selected service is found to be delivered below customer expectation. Like process failures, outcome failures can be interpreted objectively or subjectively by customers. Objective aspects of service outcome failures are mainly related to the service quality (i.e. whether what was promised was delivered). We labeled these objective failures service function failures, as they render the functional dimension of service (i.e. service features, costs, and performance) inadequate. However, customers may interpret the experiential aspects of service outcomes in varying personal ways (e.g. guest's interactions with host and their family during the stay). We named this group of failures service (outcome) experience failures to capture the experiential of traits of service, such as social and emotional experiences.

Service Functional Failure. Service functional failures are the second most ubiquitous failure category in our study - after customer service - and represent failures related to service promises, access to services, accuracy of service, consistency, and safety. Unlike previous studies, we only classified failures related to the service features under this category and exclude all processual failures (as they were grouped with process failure category in this study for a better identification of recovery strategies).

Service functional failures accounted for $34 \%$ of service failures reported in our dataset (e.g. "Host lied about place... prior to cancel [sic] reservation" or "Photos did not match the place as it was dirty"). Here, service promises was the subgrouping with high number of evidences in our dataset (29\%) and were constituted by promises such as cleanliness, security, 
amenities, consistency, privacy, access, location, size, and quietness (e.g. "AirBnB did not know about hosts Bedbugs and Scabies"). The second group, service value, reflected the inability of Airbnb to provide the promised value of money, fee comparability, or failure to refund the fair monetary means to dissatisfied customers (e.g. "Early cancellation still lead to high fee. No detail on the fees").

As expected, we observed customer comments that reported these two failures (promises and value) at the same time (e.g. cost was high considering the lack of privacy). However, there were stories that customers were only unhappy with either the failure to deliver what was promised, or the value of the money they spent based on actual accommodation. These failures, reflected in collected customer reviews, typically coincided with other failures such as customer support failure. Therefore, while process failures themselves may not lead to outcome failures, outcome failures may result in process failures if not handled well.

Service (Outcome) Experience Failure. Service (outcome) experience failures occur when, for example, a host failed to stage experiences in the manner that meet guests' experiential needs. Characteristics of such staged experiences are friendliness, helpfulness, pleasantness, and ability to accommodate. These experiential traits underscore the importance of interpersonal skills, knowledge of the property and its surrounding area. Further, they demonstrate an accommodation to customers' special needs and circumstances. It is unreasonable to classify these failures as functional since customers interpret these failures subjectively.

Three categories of service (outcome) experience failures emerged from our analysis, reported in $19 \%$ of stories, as being highly significant experiential modifiers to customers: social, emotional, and behavioral (act) experiences. Failures related to these experiences were often reported in conjunction with functional issues that reinforced customers' negative perceptions. Although these categories cannot encompass the entire domain of service experience, they were the primary experience attributes that motivated guests to write negative reviews.

The first group of service experience failures was associated with social experiences (e.g. the interaction with host or socializing with other guests). Our analysis showed that negative social experiences formed when the host failed to meet and greet the guest when expected. The second group was related to the emotional appeal of service, for example, when the guest or host failed to maintain the expected friendliness or respect (e.g. "The owner was uncooperative and uncaring with tenants"). These failures triggered negative emotional experiences, although they did not necessarily result in formal complaints (formal complaints were reported as part of other functional issues), however factors such as room décor or surprise welcome packages were cited as sources of customer delight. The third group of service experience failures was closely related to behavioral (act) experiences. The negative act experiences emerged when the guest or host needed to take additional actions to satisfy a need ("had to help the owner clean the place for the other party that would show up"). Other examples included when a promised amenity was provided and functional, but the guest needed to learn how to use it; or when the security system was helpful but difficult to disarm.

\subsection{Recovery Strategies}

When a service failure occurs, a customer will expect to be compensated for the inconvenience through what we refer to here as a recovery strategy. These strategies seek to resolve customers' complaints and decrease tangible or intangible losses by offering explanations and reimbursement for the inadequate product, service, or experience [18]. The recovery strategy chosen by a firm is dependent upon the specific category and subcategory of service failure reported. In this study, we attempt to match failures with possible recovery strategies.

Cost Recovery. Cost recovery is an effective recovery strategy in the sharing economy, especially in the case service outcome failures. Three cost recovery strategies were observed in sharing economy literature, ranging from Refund (i.e. reimbursement of funds spent), Credit (i.e. affordance of funds for future purchase) or Discount (i.e. reduction of funds necessary for future transactions). In the case of Airbnb, the main cost recovery strategy used was full or partial refund depending on the host cancelation policy. Study results showed that in the case of service failures, guests expected refund; when the failure was related to service functional failure, they expected full and immediate refund; when the failure was attributed to service (outcome) experiences, they hoped for a credit or discount. We are not able to identify cost recovery applications in process failures except when the customers (guests and hosts) experienced system error in reservation or cancelation.

Outcome Recovery. Outcome recovery is defined here as a firm offering customers an alternative option (e.g. alternative accommodation) or address the functional or performance issues (i.e. enforced repair). An outcome recovery strategy was mainly expected after service functional failures; however, it was also instrumental in other cases of failures such as service acquisition experience failure. Outcome recoveries 
have the potential to negate or even invert customer dissatisfaction through reliable and timely customer service. Three forms of outcome recovery strategy were observed in this study: Replacement, Enforced repair, Promised repair, and Resolution.

Replacement was a recovery strategy that focused on finding an alternative accommodation option for unhappy customers (while our data showed this expectation among customers, no one reported such support from Airbnb in our dataset). Enforce repair is the straightforward act of fixing an issue in both service outcome and serves process (e.g. to recover service acquisition failures). Promised or delayed repair addresses issues mainly related to a process failure (such as fixing a technical issue on the platform) and provide additional support to complete a request. Unlike enforced repair, (which focused on service outcome failures) it is relatively immediate, promised repair is centered around process failures and requires time to be managed. Resolution refers to the strategy of intermediation between guests and hosts for a short-term solution (e.g. accommodation of a request based on the listed promises on the platform).

Relationship Recovery. Safeguarding the relationship between platform and consumer from damage done by service failures is of the utmost importance to businesses engaged in sharing economy models. As such, relationship recovery strategies are an absolute necessity to the long-term viability of a sharing economy business. Three major relationship recovery strategies were observed in this study: Rebuild, Correction Plus, and Process Control. These strategies were either practiced by Airbnb to address an issue or expected by the customers.

Rebuild is, as the name suggests, a recovery strategy wherein the platform gives an unhappy customer a special offer-mainly after service outcome failures - to rebuild the relationship and regain the customer's trust. Correction plus recovers technology or service acquisition failures by not only rectifying the issue, but by providing additional services or opportunities to boot. Finally, process control focuses on cooperative communication with customers (mainly hosts), to come to a mutual agreement about the best course of action to resolve an issue. This recovery strategy is associated with recovering failures of service functional outcomes

\section{Discussion and Implications}

This study shows the negative consequences of service failures in the sharing economy and the importance of service failure recovery in keeping positive brand image and competitive advantage. Using Airbnb as a case example, we analyzed customer reviews to identify the most significant types of service failure complaints and possible recovery strategies for each. We identified two main categories of failures: process failures and outcome failures. We showed that process failures are associated with the performance of the platform technology or 'service technology' and can be evaluated objectively. Otherwise, process failures dealing with 'service acquisition' process are mainly interpreted by customers subjectively. The study also revealed that outcome failures refer to either 'service function' failures or 'service experience' failures, where former is mainly attributed to the objective aspects of service quality and latter to subjective and experiential traits of service. The results of our inquiry support prioritizing the bottom-line delivery of service functionalities and performance factors. However, we recognize that the enhancement of the experiential factors is as important as performance factors in the context of service failures management. Figure 1 summarizes these findings.

\begin{tabular}{c|c|c|}
\multicolumn{1}{c}{ Objective } & \multicolumn{1}{c}{ Process } & \multicolumn{1}{c}{ Outcome } \\
\cline { 2 - 3 } & $\begin{array}{c}\text { Service } \\
\text { Technology }\end{array}$ & $\begin{array}{c}\text { Service } \\
\text { Function }\end{array}$ \\
\cline { 2 - 3 } Subjective & $\begin{array}{c}\text { Service } \\
\text { Acquisition }\end{array}$ & $\begin{array}{c}\text { Service } \\
\text { Experience }\end{array}$ \\
\hline
\end{tabular}

Figure 1. Service failure from users' perspective in the sharing economy (case of Airbnb)

We also identified, offered, or expected three recovery strategies: Cost recovery, outcome recovery and relationship recovery. Our results demonstrated that cost recovery is the best strategy in the presence of service outcome failures; service acquisition and experience failures can be addressed best by outcome recovery; and relationship recovery can be used in case of both process and outcome failures. We further argue for the need to explore relationship recovery to reinstitute the customers into repurchasing sooner after a failure has been experienced. However, it seems the main challenge to formalize some recovery strategies is the lack of pattern among customers' expectation. This variation makes it extremely difficult for platforms to come up with uniform recovery strategies for each failure. The findings also showed while cost recovery was expected in many cases, the platform failures in outcome recovery (or in a few cases relationship recovery) was the reason behind the complaints. We found that many guests contacted the platform with outcome recovery related solution(s). However, Airbnb either dismissed the complaints or tried address that with a cost recovery 
option. Doing so, Airbnb failed to satisfy the customer hence, very negative reviews.

This study adds nuance to our understanding of service failures beyond the known functioninformation -system failures in an ecommerce context. We argue that beyond varying types and degrees of 'mechanical' failures, sharing economy platforms must contend with experience failure as well. Despite the ample evidence in both theory and practice, service experience failures remain serious unaddressed issues pertaining to consumer retention in the sharing economy. The sharing economy mainstays are increasingly popular in places like Hawaii not only because of offering a broader range of prices but also for being inherently more integrated into local lifestyle and values. This offers new possibilities to minimize the negative impact of service failures by understanding the customers' experiential needs.

Furthermore, in the sharing economy, service experience is co-created by a platform provider, a peer service provider and a customer. Therefore, platform owners, as the main resource integrator, should find solutions to common service failures by involving all the stakeholders including their frontline employees and peer-service providers. The recovery strategies, therefore, can be achieved through an orientation that places empowered employees and peers at center stage. From a practical perspective, clearer guidelines on what to anticipate and what not to anticipate from the service providers could also give the customers more trust when using such services.

The success of recovery strategies also depends upon a platform's ability to seamlessly converse with the customer in both physical and virtual worlds simultaneously. Platforms should be prepared to adapt quickly and re-engineer the delivery of service experiences based on what customers acquire and use. This is especially important in the lodging industry, whose product is to a large extent, a "home away from home" experience. At a macro level, lodging firms need to match, if not exceed, guests' lifestyles.

\section{Conclusion and Future Research}

Service failures will not be a breaking point for sharing economy platforms if they are systematically monitored and diligently recovered with an appropriate strategy. As digital technology continues to drive the growth of sharing economy platforms, significant emphasis must be placed on how these firms manage customer experience, specifically in relation to unavoidable service failures. This study provides potential groundwork for future research. For example, examining and refining the concepts proposed here in other sharing economy contexts might help future research to develop a more generalizable framework. Future researchers may also examine the severity of specific service failure categories on different customer performance indicators such as retention. Research of this variety may enable managers and service providers to more accurately proact and react to service failures that are common for their market. Lastly, the results presented here do not address longitudinal capabilities for sustained service failure correction. As such, following iterations of this research ought to identify what long-term strategies might be implemented to preempt any service failures going forward.

\section{References}

[1] D. Dredge and S. Gyimóthy, "The collaborative economy and tourism: Critical perspectives, questionable claims and silenced voices," Tour. Recreat. Res., vol. 40, no. 3, pp. 286302, Sep. 2015.

[2] O. Gerwe and R. Silva, "Clarifying the Sharing Economy: Conceptualization, Typology, Antecedents, and Effects," Acad. Manag. Perspect., vol. 34, no. 1, pp. 65-96, Feb. 2020.

[3] K. Frenken and J. Schor, "Putting the sharing economy into perspective," Environ. Innov. Soc. Transitions, vol. 23, pp. 310, Jun. 2017.

[4] F. Bardhi and G. M. Eckhardt, "Access-Based Consumption: The Case of Car Sharing: Table 1.," J. Consum. Res., vol. 39, no. 4, pp. 881-898, 2012.

[5] R. Belk, "Sharing: Table 1," J. Consum. Res., vol. 36, no. 5, pp. 715-734, Aug. 2010.

[6] A. Sundararajan, The Sharing Economy: The End of Employment and the Rise of Crowd-Based Capitalism. Cambridge: MIT Press, 2016.

[7] K. Täuscher and J. Kietzmann, "Learning from failures in the sharing economy," MIS Q. Exec., vol. 16, no. 4, pp. 253-264, 2017.

[8] K. Abhari, E. J. Davidson, and B. Xiao, "Collaborative innovation in the sharing economy: Profiling social product development actors through classification modeling," Internet Res., vol. 29, no. 5, pp. 1014-1039, 2019.

[9] S. Sands, C. Ferraro, C. Campbell, J. Kietzmann, and V. V. Andonopoulos, "Who shares? Profiling consumers in the sharing economy," Australas. Mark. J., 2020.

[10] A. Suri, B. Huang, and S. Sénécal, "I Can Forgive You, But I Can't Forgive the Firm: An Examination of Service Failures in the Sharing Economy," J. Mark. Theory Pract., vol. 27, no. 4, pp. 355-370, 2019.

[11] K. Täuscher and J. Kietzmann, "Learning from Failures in the Sharing Economy," MIS Q. Exec., vol. 16, no. 4, pp. 253-263, 2017.

[12] T. Furunes and M. Mkono, "Service-delivery success and failure under the sharing economy," Int. J. Contemp. Hosp. Manag., vol. 31, no. 8, pp. 3352-3370, 2019.

[13] C. Ennew and K. Schoefer, "Service Failure and Service Recovery in Tourism: A Review," in The Tourist: A Psychological Perspective, Tourism and Travel Research Institute, A. Jaj, Ed. Nottingham, 2004.

[14] V. Kumar, A. Lahiri, and O. B. Dogan, "A strategic framework for a profitable business model in the sharing economy," Ind. Mark. Manag., vol. 69, pp. 147-160, 2018.

[15] D. M. Running, J. B. Ligon, and I. Miskioglu, "Antecedents to Customer Expectations for Service Recovery," J. Compos. Mater., vol. 33, no. 10, pp. 928-940, 1999.

[16] B. Vine, The Routledge handbook of language in the 
workplace. 2017.

[17] R. L. Hess, S. Ganesan, and N. M. Klein, "Service failure and recovery: The impact of relationship factors on customer satisfaction," J. Acad. Mark. Sci., vol. 31, no. 2, pp. 127-145, 2003.

[18] Z. Zhu, K. Sivakumar, and A. Parasuraman, "A mathematical model of service failure and recovery strategies," Decis. Sci., vol. 35, no. 3, pp. 493-525, Aug. 2004.

[19] R. Casidy and H. Shin, "The effects of harm directions and service recovery strategies on customer forgiveness and negative word-of-mouth intentions," J. Retail. Consum. Serv. vol. 27, pp. 103-112, 2015.

[20] P. G. Patterson, E. Cowley, and K. Prasongsukarn, "Service failure recovery: The moderating impact of individual-level cultural value orientation on perceptions of justice," Int. J. Res. Mark., vol. 23, no. 3, pp. 263-277, 2006.

[21] S. Hyken, "What Customers Want And Expect," Forbes, 2018.

[22] C. W. Tan, I. Benbasat, and R. T. Cenfetelli, "An exploratory study of the formation and impact of electronic service failures," MIS Q. Manag. Inf. Syst., vol. 40, no. 1, pp. 1-29, 2016.

[23] R. Johnston and S. Michel, "Three outcomes of service recovery: Customer recovery, process recovery and employee recovery," Int. J. Oper. Prod. Manag., vol. 28, no. 1, pp. 79 99, Jan. 2008.

[24] A. Malhotra and C. Malhotra, "Evaluating customer information breaches as service failures: An event study approach,” J. Serv. Res., vol. 14, no. 1, pp. 44-59, Nov. 2011.

[25] A. V. Muthukrishnan and A. Chattopadhyay, "Just give me another chance: The strategies for brand recovery from a bad first impression,” J. Mark. Res., vol. 44, no. 2, pp. 334-345, May 2007.

[26] J. E. Collier and C. C. Bienstock, "Measuring service quality in E-retailing," J. Serv. Res., vol. 8, no. 3, pp. 260-275. 2006.

[27] R. L. Oliver, "Satisfaction: a behavioral perspective on the consumer," Choice Rev. Online, vol. 47, no. 12, 2010

[28] S. Rao, S. E. Griffis, and T. J. Goldsby, "Failure to deliver? Linking online order fulfillment glitches with future purchase behavior," J. Oper. Manag., vol. 29, no. 7-8, pp. 692-703, 2011.

[29] J. L. Miller, C. W. Craighead, and K. R. Karwan, "Service recovery: A framework and empirical investigation," J. Oper. Manag., vol. 18, no. 4, pp. 387-400, 2000.

[30] Z. Zhu, C. Nakata, K. Sivakumar, and D. Grewal, "Fix It or Leave It? Customer Recovery from Self-service Technology Failures," J. Retail., vol. 89, no. 1, pp. 15-29, 2013.

[31] W. H. DeLone and E. R. McLean, "The DeLone and McLean model of information systems success: A ten-year update," in Journal of Management Information Systems, 2003, vol. 19, no. 4, pp. 9-30.

[32] A. Nili, M. Tate, and G. G. Gable, "A typology of technological enablers of website service failure prevention," in Proceedings - Pacific Asia Conference on Information Systems, PACIS 2014, 2014, no. February 2017.

[33] C. Zhang, W. J. Kettinger, P. Kolte, S. Yoo, W. J. Kettinger, and S. Yoo, "Established Companies' Strategic Responses to Sharing Economy Threats.," MIS Q. Exec., vol. 17, no. 1, pp. $23-40,2018$

[34] T. Laleh, J. Paquet, S. Mokhov, and Y. Yan, "Constraint verification failure recovery in web service composition," Futur. Gener. Comput. Syst., vol. 89, pp. 387-401, 2018.

[35] R. Bougie, R. Pieters, and M. Zeelenberg, "Angry Customers don't Come Back, They Get Back: The Experience and Behavioral Implications of Anger and Dissatisfaction in Services," J. Acad. Mark. Sci., vol. 31, no. 4, pp. 377-393, 2003.

[36] A. Sears, J. A. Jacko, and E. M. Dubach, "International aspects of world wide web usability and the role of high-end graphical enhancements," Int. J. Hum. Comput. Interact., vol. 12, no. 2 , pp. 241-261, Jun. 2000.

[37] F. F. H. Nah, "A study on tolerable waiting time: How long are Web users willing to wait?," in Behaviour and Information Technology, 2004, vol. 23, no. 3, pp. 153-163.

[38] B. B. Holloway and S. E. Beatty, "Service Failure in Online Retailing: A Recovery Opportunity," J. Serv. Res., vol. 6, no. 1, pp. 92-105, Aug. 2003.

[39] G. L. Martin and K. G. Corl, "System response time effects on user productivity," Behav. Inf. Technol., vol. 5, no. 1, pp. 313, Jan. 1986.

[40] A. Douglas, L. Muir, and K. Meehan, "E-quality in the eservices provision of legal practices," Manag. Serv. Qual. An Int. J., vol. 13, no. 6, pp. 483-491, Jan. 2003.

[41] C. Grönroos, "From Marketing Mix to Relationship Marketing: Towards a Paradigm Shift in Marketing," Manag. Decis., vol. 32, no. 2, pp. 4-20, Jan. 1994.

[42] R. T. Cenfetelli, I. Benbasat, and S. Al-Natour, "Addressing the what and how of online services: Positioning supportingservices functionality and service quality for business-toconsumer success," Inf. Syst. Res., vol. 19, no. 2, pp. 161-181, Jun. 2008

[43] A. M. Susskind, "Consumer Frustration in the CustomerServer Exchange: The Role of Attitudes Toward Complaining and Information Inadequacy Related to Service Failures," $J$. Hosp. Tour. Res., vol. 28, no. 1, pp. 21-43, Feb. 2004.

[44] H. H. Chang and S. W. Chen, "The impact of customer interface quality, satisfaction and switching costs on e-loyalty: Internet experience as a moderator," Comput. Human Behav., vol. 24, no. 6, pp. 2927-2944, 2008.

[45] C. W. Tan, I. Benbasat, and R. T. Cenfetelli, "It-mediated customer service content and delivery in electronic governments: An empirical investigation of the antecedents of service quality," MIS Q. Manag. Inf. Syst., vol. 37, no. 1, pp. 77-109, 2013.

[46] D. A. Collier, The service/quality solution: using service management to gain competitive advantage. Irwin Professional Publishing, 1994.

[47] S. Dakhlia, A. Davila, and B. Cumbie, "Trust, but verify: The role of ICTs in the sharing economy," in Lecture Notes in Information Systems and Organisation, vol. 15, Springer Heidelberg, 2016, pp. 303-311.

[48] J. Camilleri and B. Neuhofer, "Value co-creation and codestruction in the Airbnb sharing economy," Int. J. Contemp. Hosp. Manag., vol. 29, no. 9, pp. 2322-2340, 2017.

[49] T. Liao and K. Xu, "A process approach to understanding multiple open source innovation contests - Assessing the contest structures, execution, and participant responses in the android developer challenges," Inf. Organ., vol. 30, no. 2, 2020.

[50] S. Sengupta and C. Haythornthwaite, "Learning with Comments: An Analysis of Comments and Community on Stack Overflow," in Proceedings of the 53rd Hawaii International Conference on System Sciences, 2020, vol. 3, pp. 2898-2907.

[51] C. M. Voorhees et al., "Service encounters, experiences and the customer journey: Defining the field and a call to expand our lens," J. Bus. Res., vol. 79, pp. 269-280, Oct. 2017.

[52] J. Kandampully, T. Zhang, and E. Jaakkola, "Customer experience management in hospitality: A literature synthesis, new understanding and research agenda," Int. J. Contemp. Hosp. Manag., vol. 30, no. 1, pp. 21-56, 2018.

[53] Y. Lee, J. Park, and B. Lee, "Battle of Sharing Economy: The Contingent Effects of Ride-Sharing on Taxi Industry," in Proceedings of the 51st Hawaii International Conference on System Sciences, 2018, vol. 9.

[54] M. Cheng, "Sharing economy: A review and agenda for future research,” Int. J. Hosp. Manag., vol. 57, pp. 60-70, 2016. 